\title{
Biomass Degradation under Ferruginous Conditions
}

\author{
Kanchi Dave, Katharine J. Thompson, Sean A. Crowe \\ UBC, Vancouver, British Columbia, Canada. \\ Departments EOAS \& M\&I, University of British Columbia \\ kanchid1111@gmail.com \\ Crowe Laboratory, University of British Columbia, Canada
}




\section{Acknowledgements}

Crowe Lab, University of British Columbia

- Aleksandra Rahman

- Amani Alsufyani

- Arne Sturm

- Ashley Davidson

- Celine Michiels

- Jenifer Spence

- Kohen Bauer

- Niko Finke

- Rachel Simister

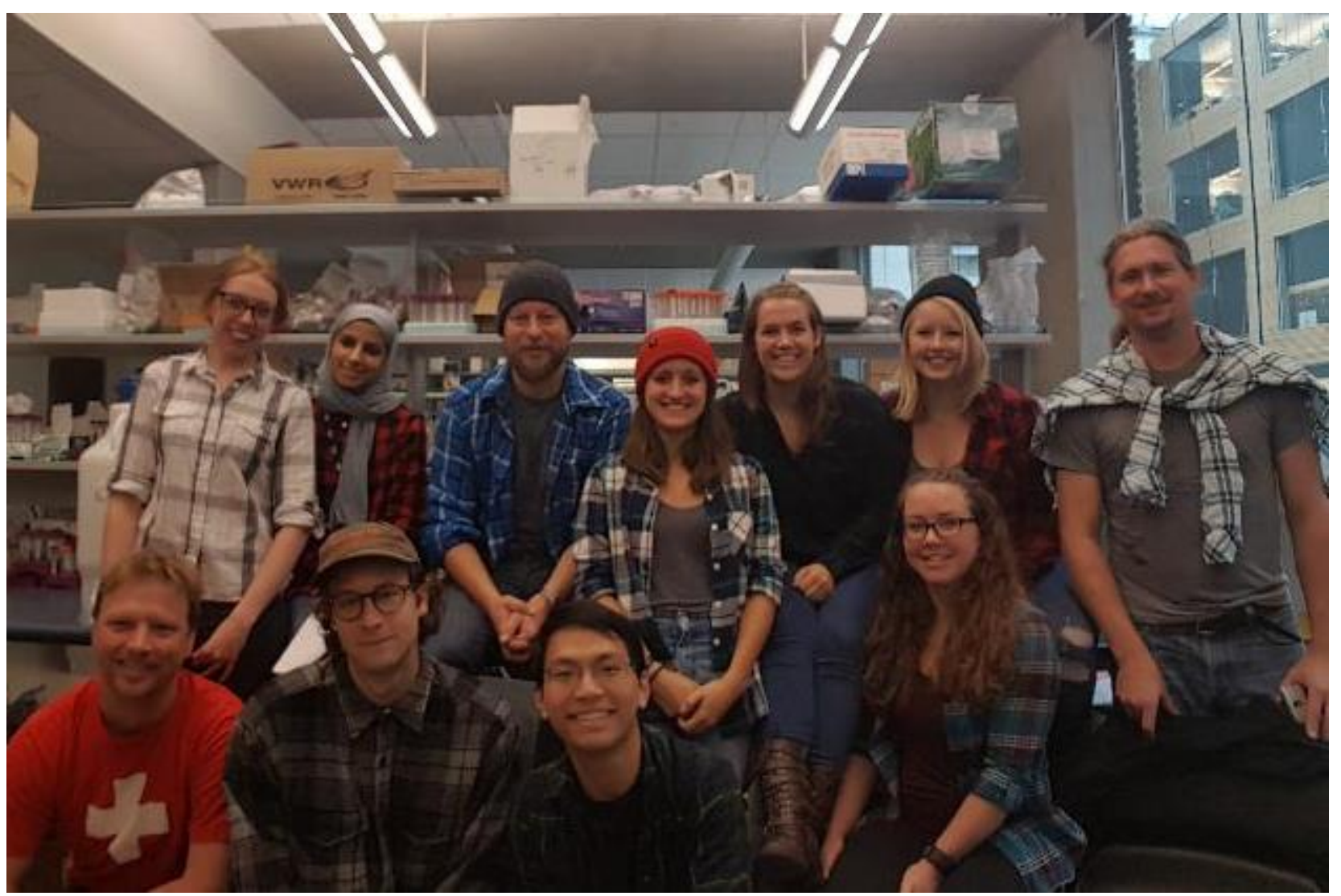

THE UNIVERSITY

OF BRITISH COLUMBIA 


\section{Evolution of Earth's atmosphere and ocean over time}

a. GOE

b.
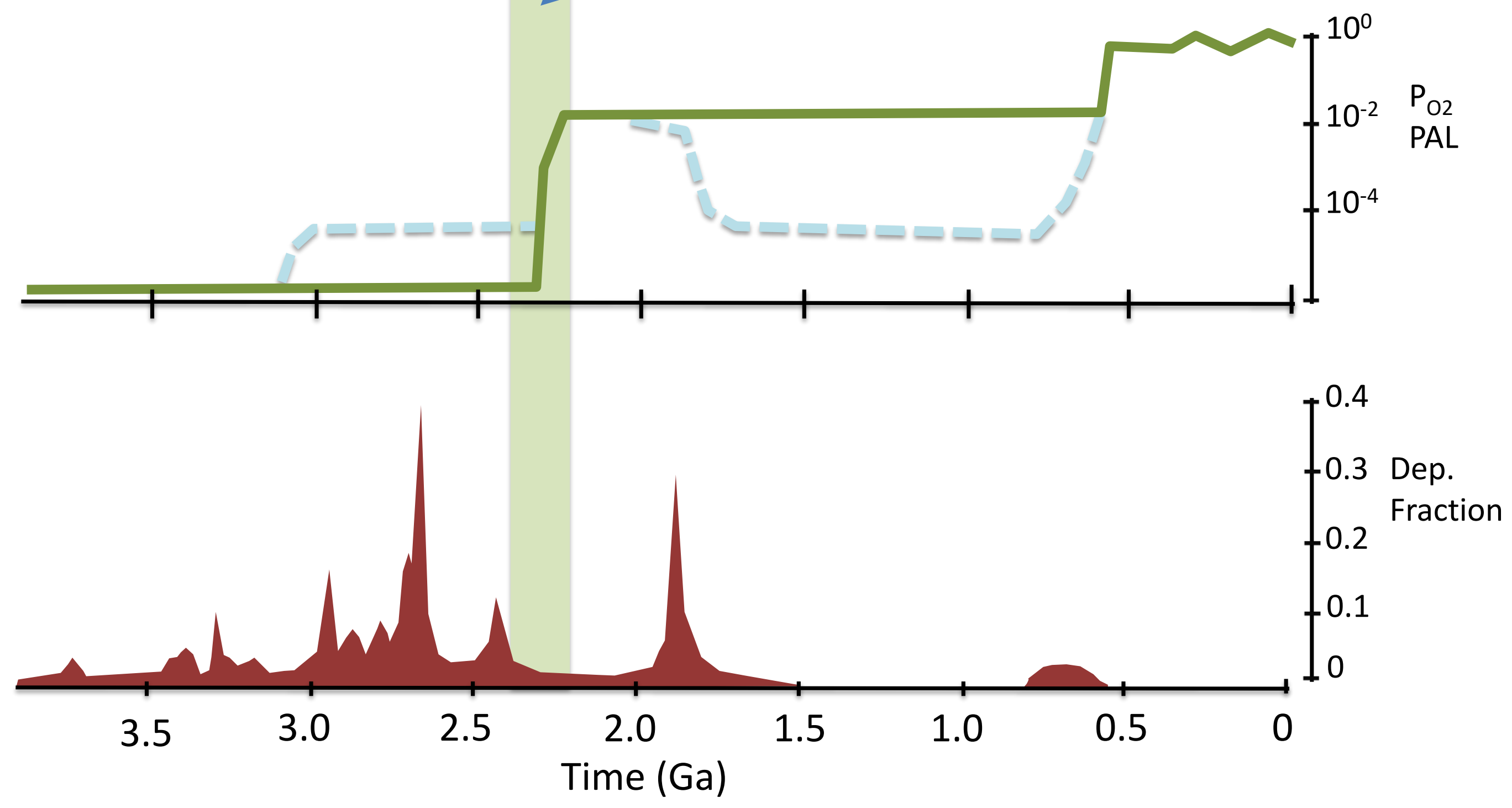
First isolates capable of photoferrotrophy
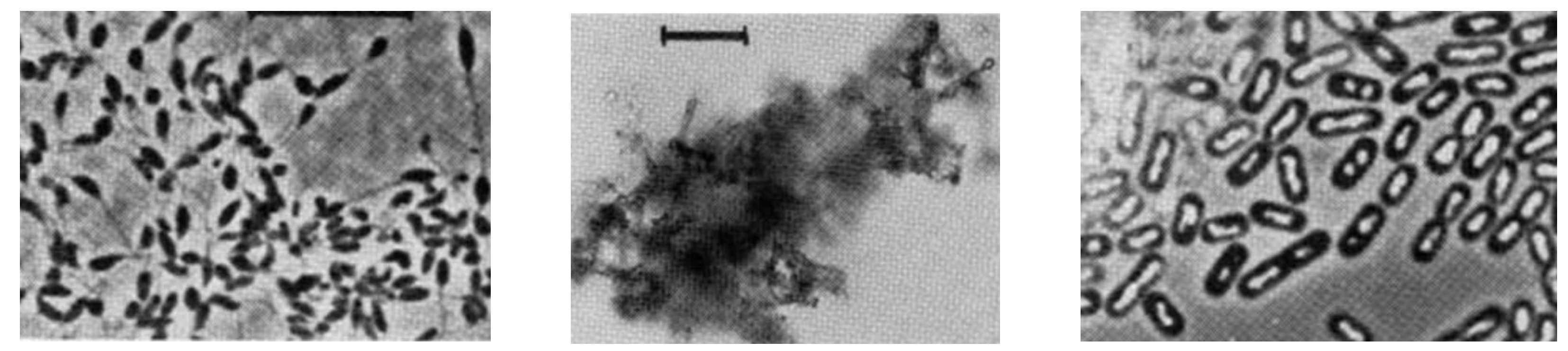

$$
\mathrm{HCO}_{3}{ }^{-}+4 \mathrm{Fe}^{2+}+10 \mathrm{H}_{2} \mathrm{O}+h v \rightarrow\left[\mathrm{CH}_{2} \mathrm{O}\right]+4 \mathrm{Fe}(\mathrm{OH})_{3}+7 \mathrm{H}^{+}
$$




\section{Oxidation rates of pure culture photoferrotrophs}
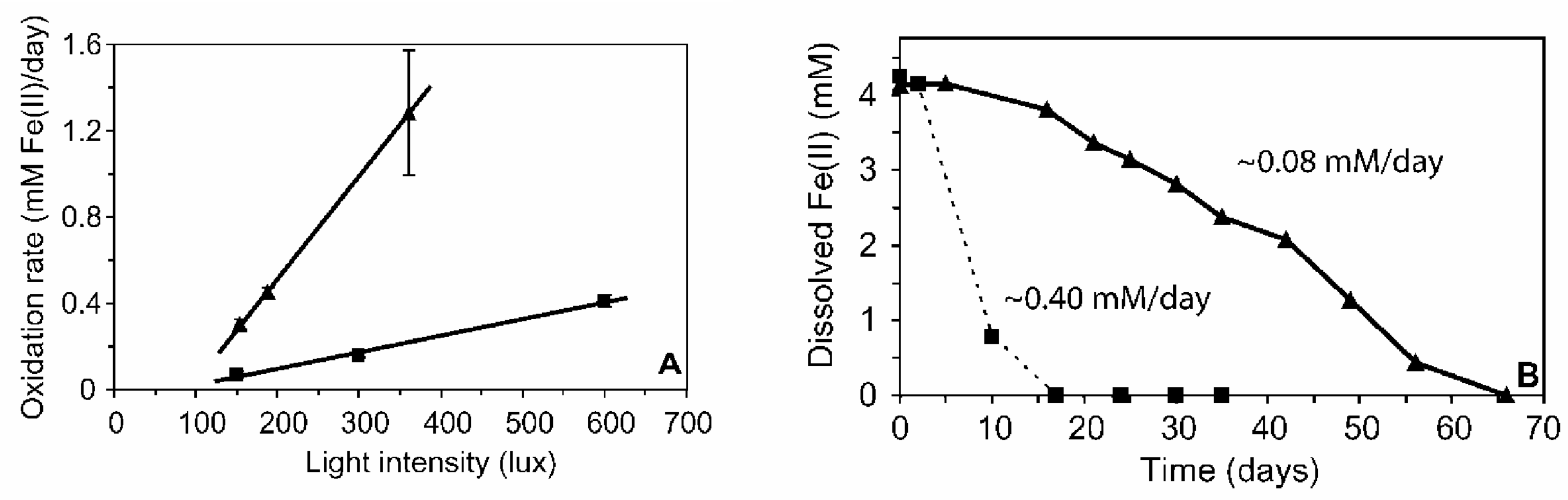


\section{Modern analogues of ferruginous archean oceans}

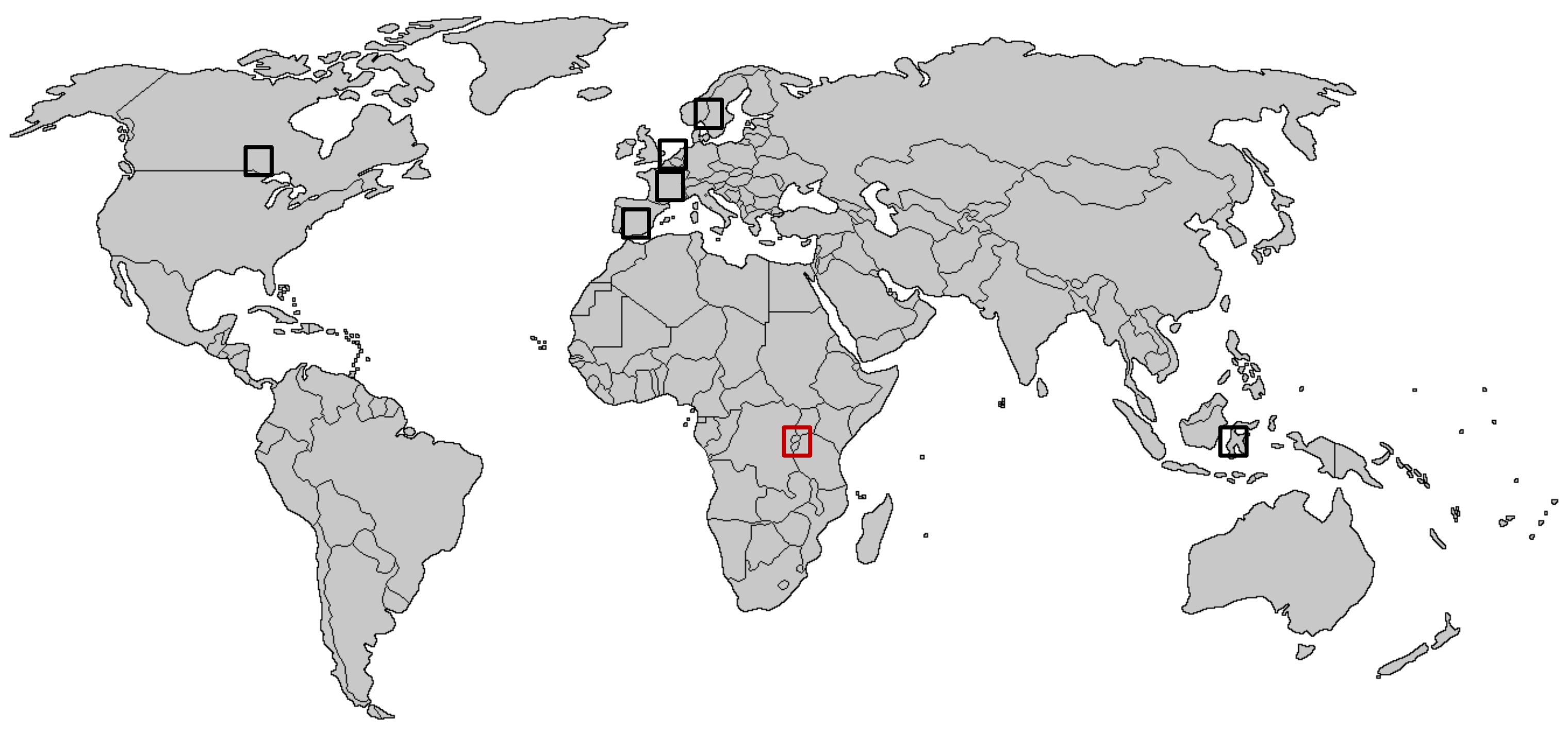




\section{Process rates at Kabuno Bay}

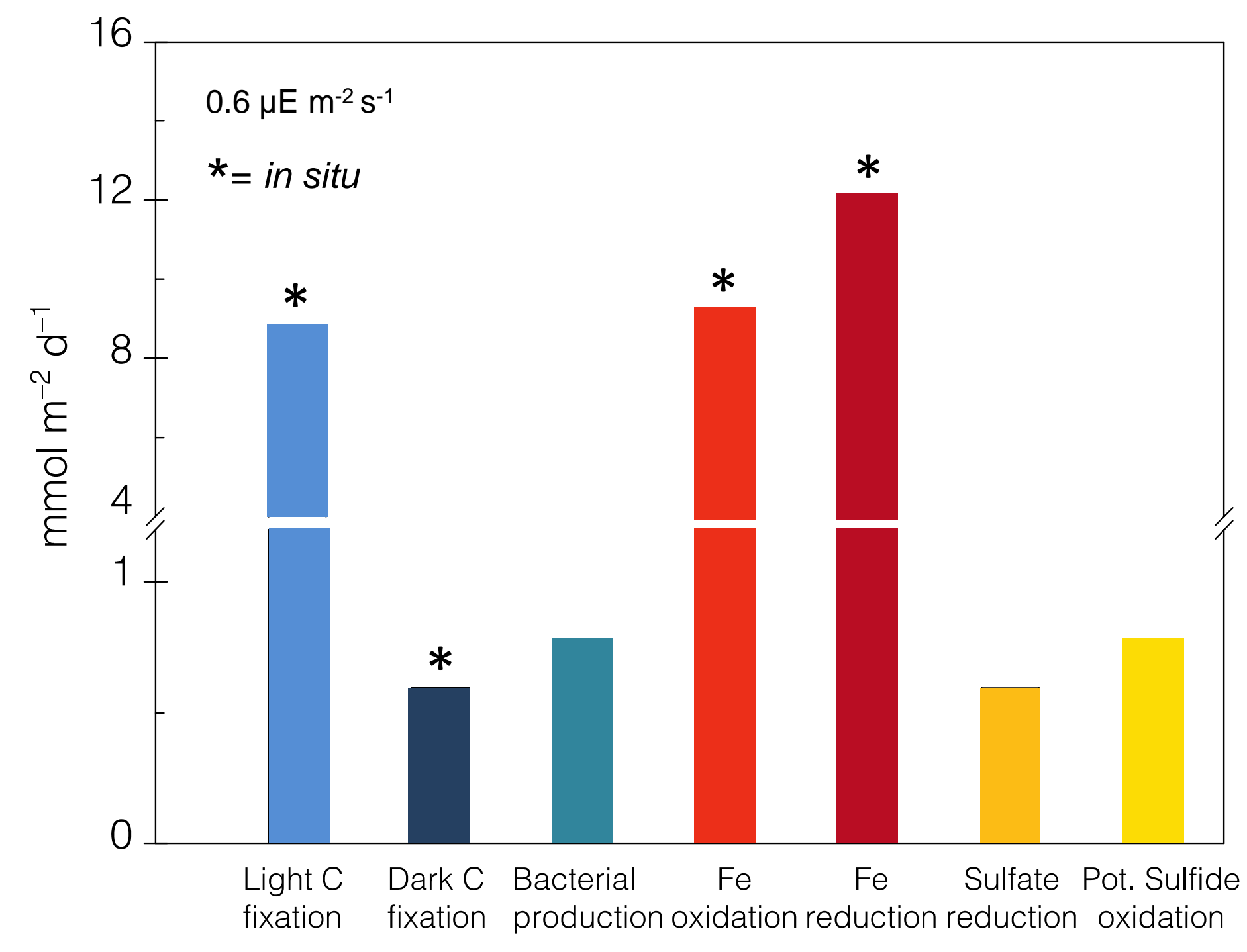

Lliros et. al., Scientific Reports, 2015 


\section{Iron-Carbon cycle model}

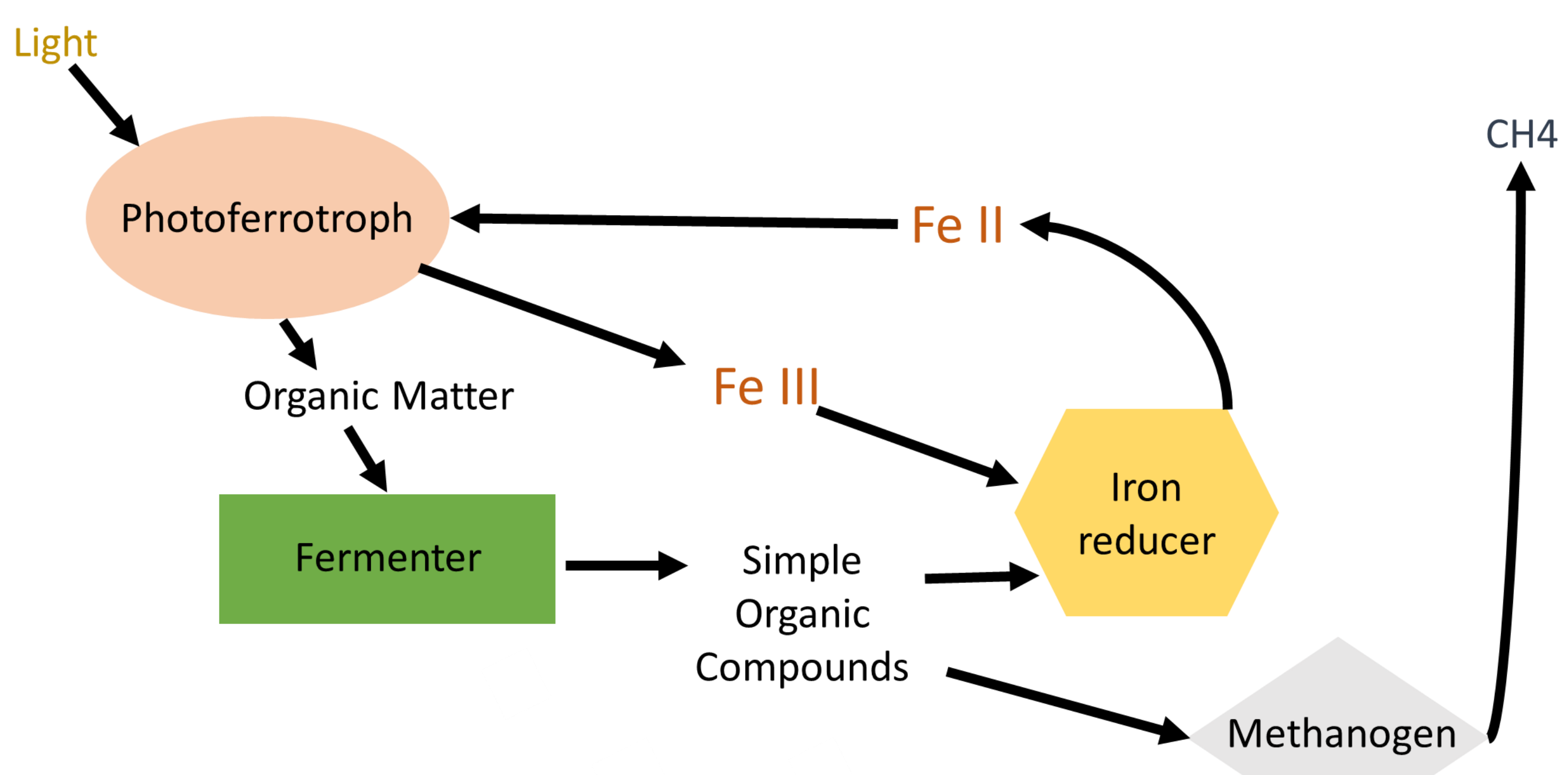




\section{Process Rates at Kabuno Bay}

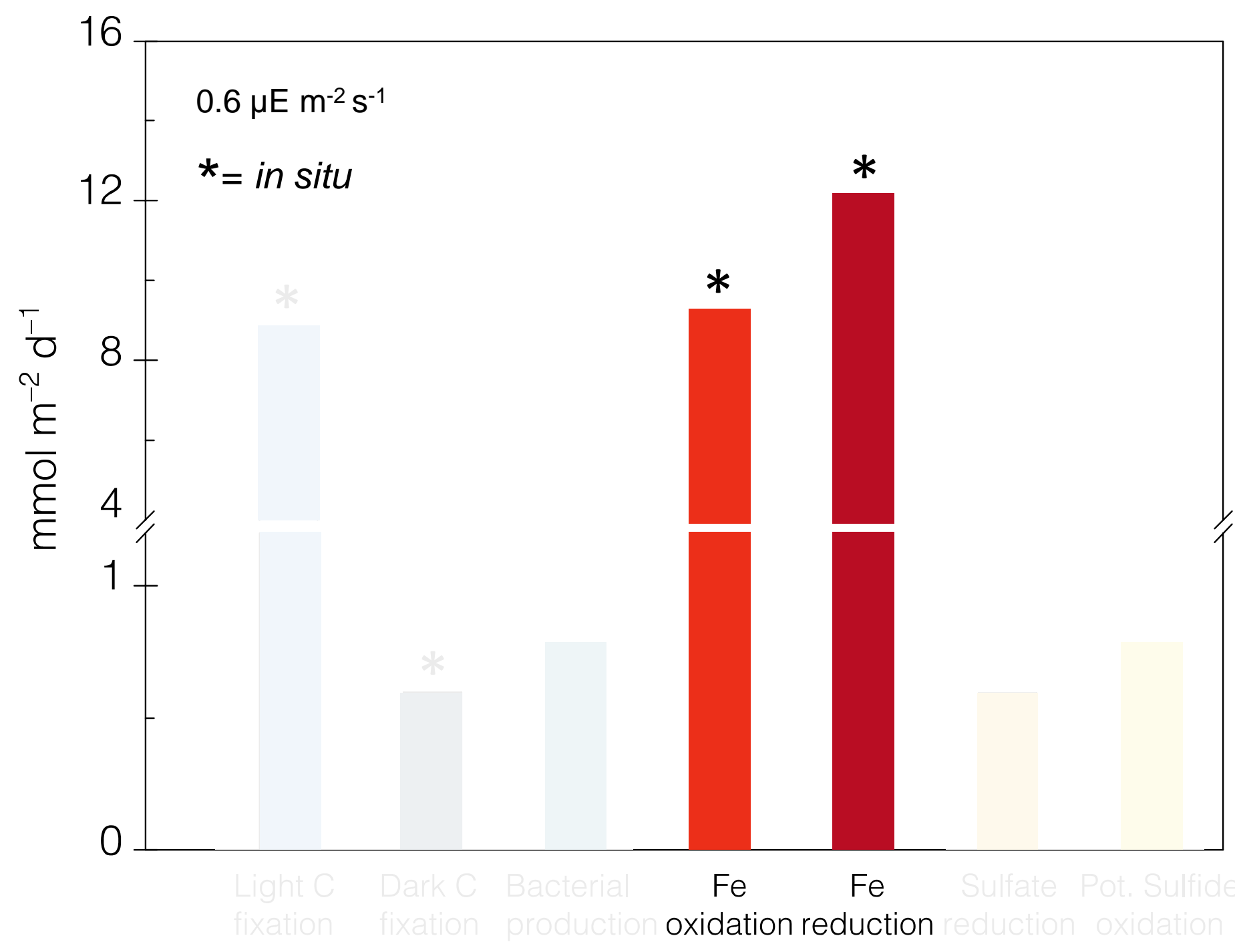

Lliros et. al., Scientific Reports, 2015 


\section{Iron-Carbon Cycle Model}

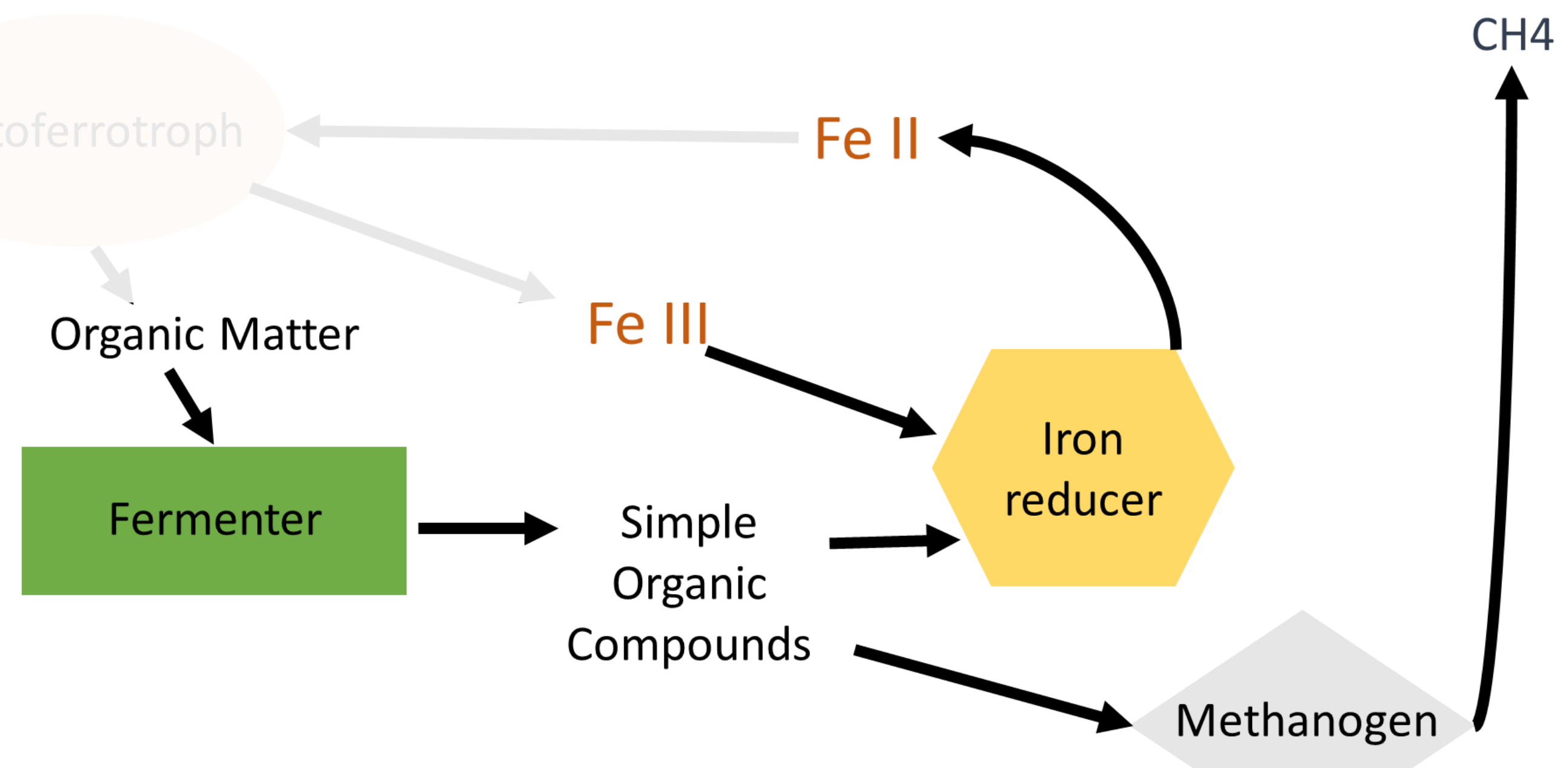




\section{Test conditions}

Methanogen conducive

$\mathrm{N}_{2} / \mathrm{CO}_{2}$
Iron reducer

conducive

Oxidant:

C.pheaoferrooxidans
Reductant: Iron III

$\mathrm{N}_{2} / \mathrm{CO}_{2}$ 


\section{Results}
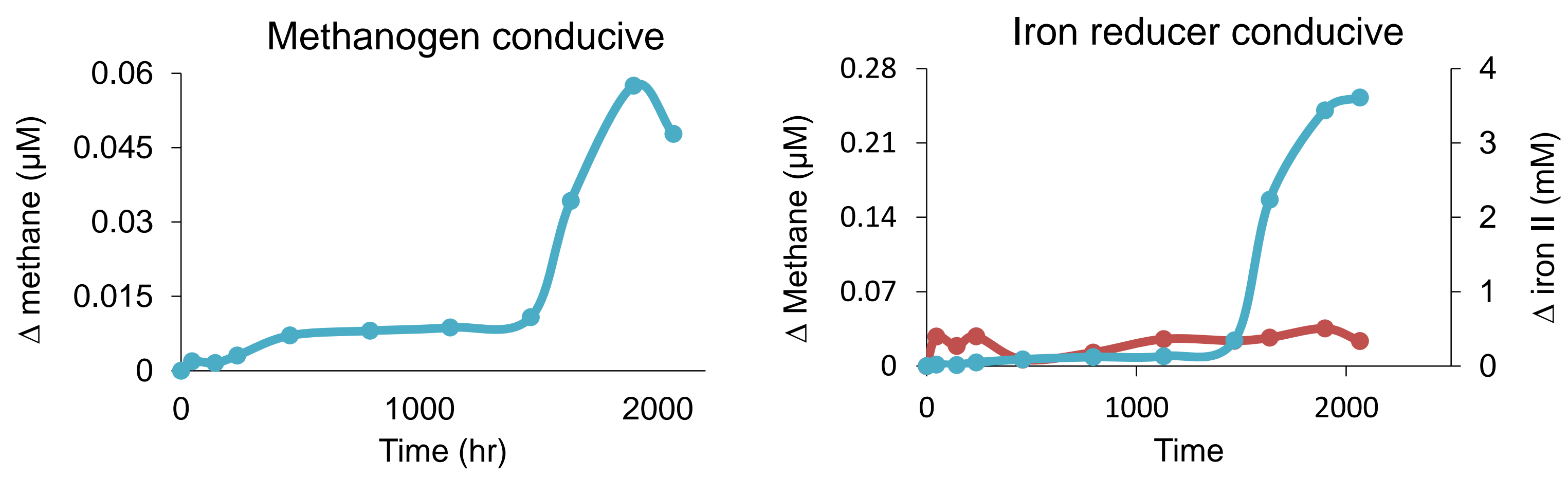

Methane Iron 


\section{Results}
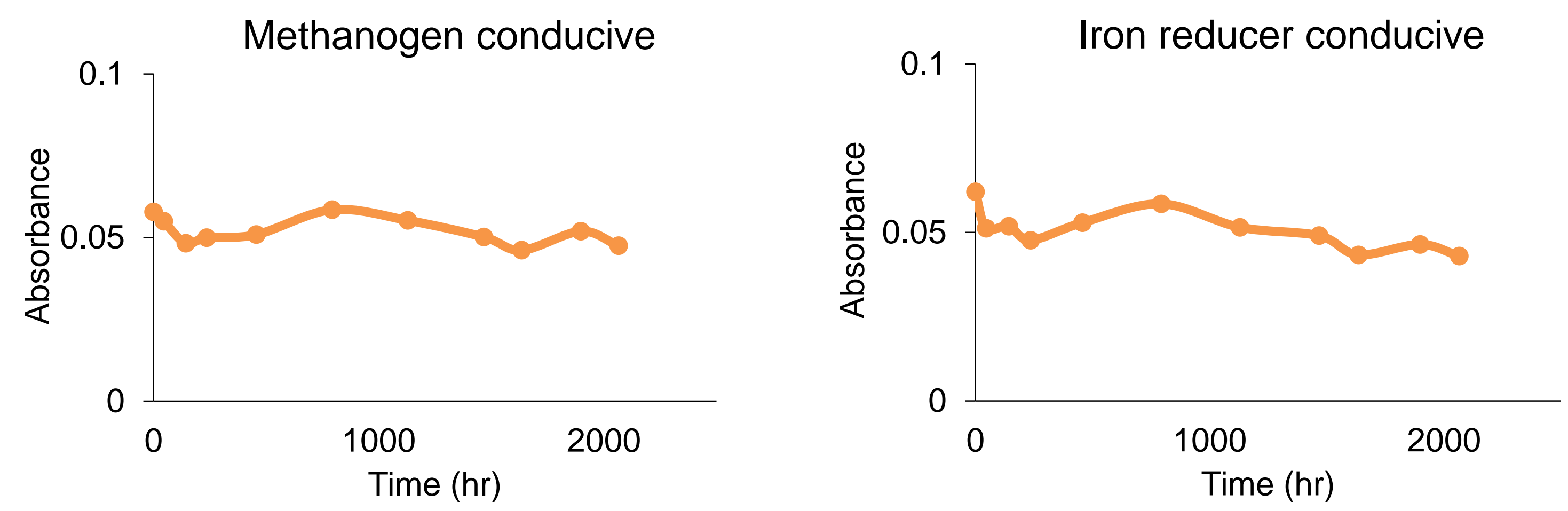

Pigments 


\section{Results}

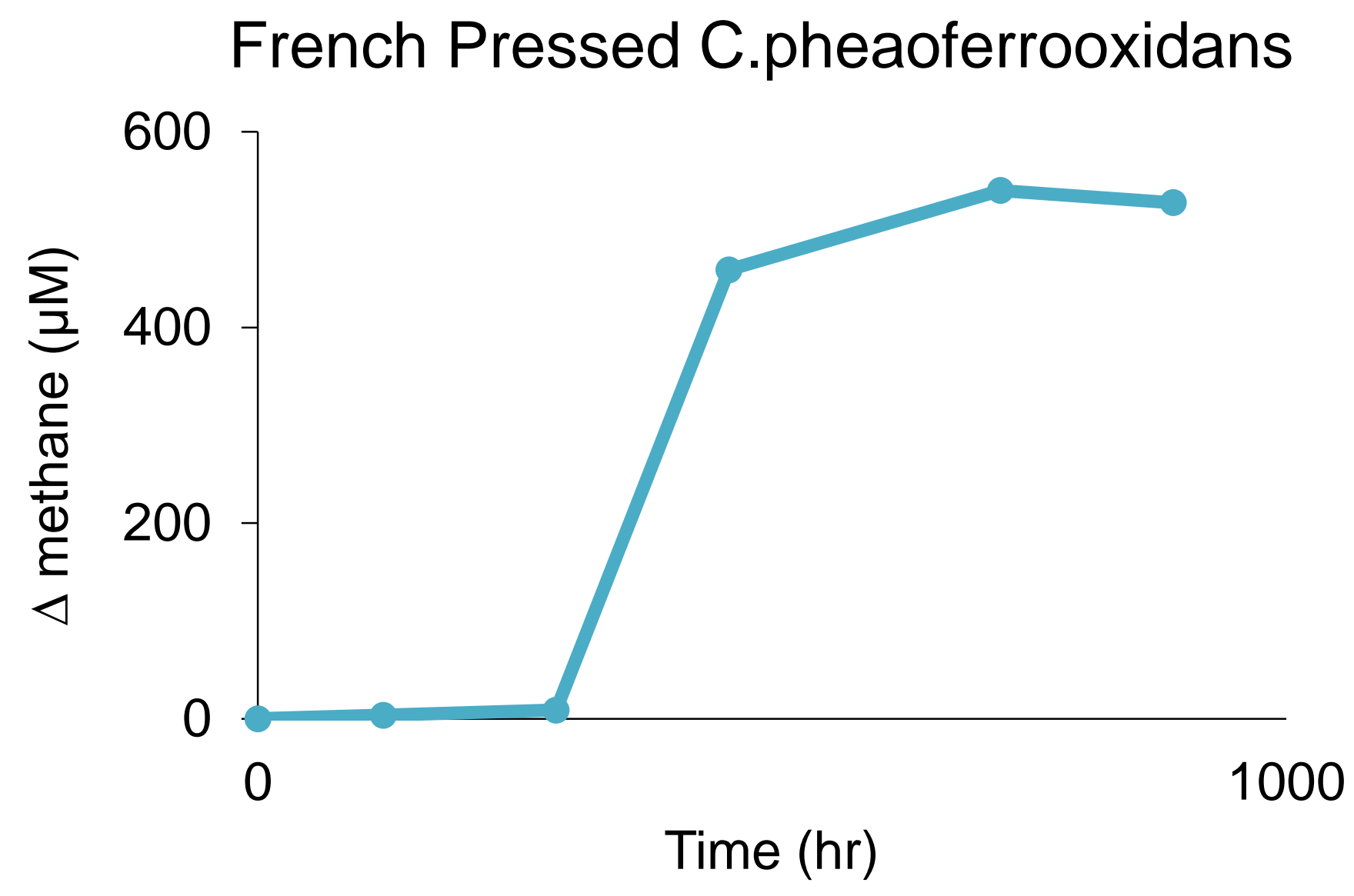

Methane 


\section{Test conditions}

Methanogen conducive

$\mathrm{N}_{2} / \mathrm{CO}_{2}$

\section{Oxidant: \\ Yeast extract \\ + acetate}

Iron reducer conducive

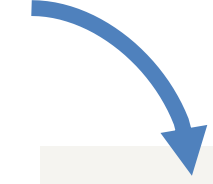

Reductant: Iron III

$$
\mathrm{N}_{2} / \mathrm{CO}_{2}
$$




\section{Results}
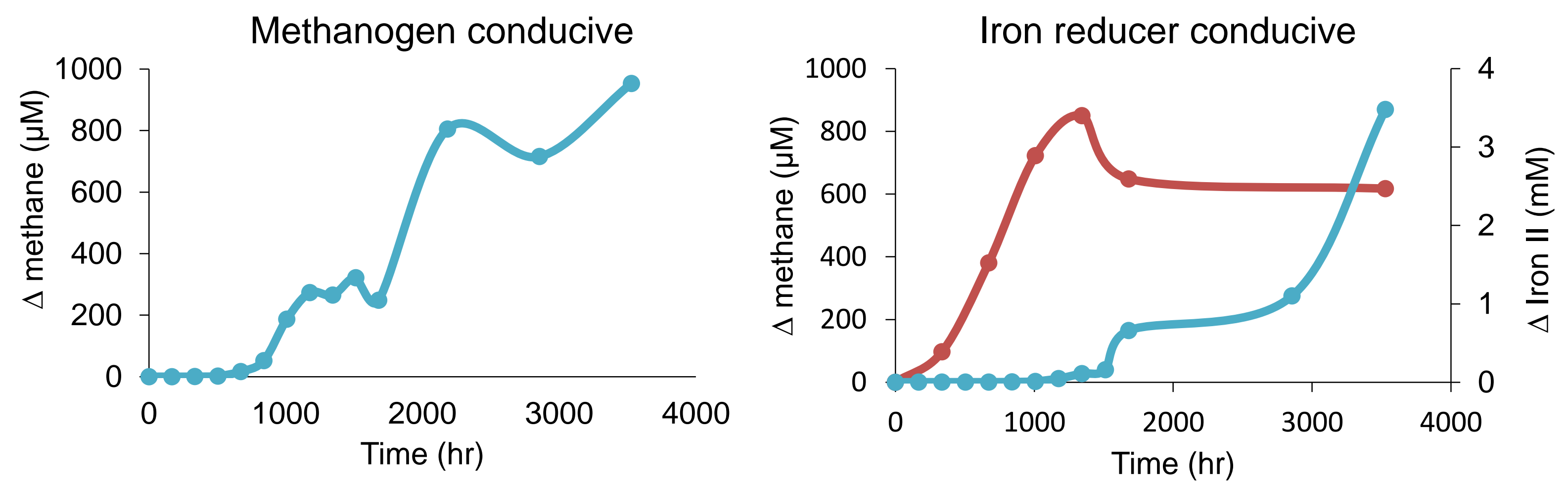


\section{DNA}
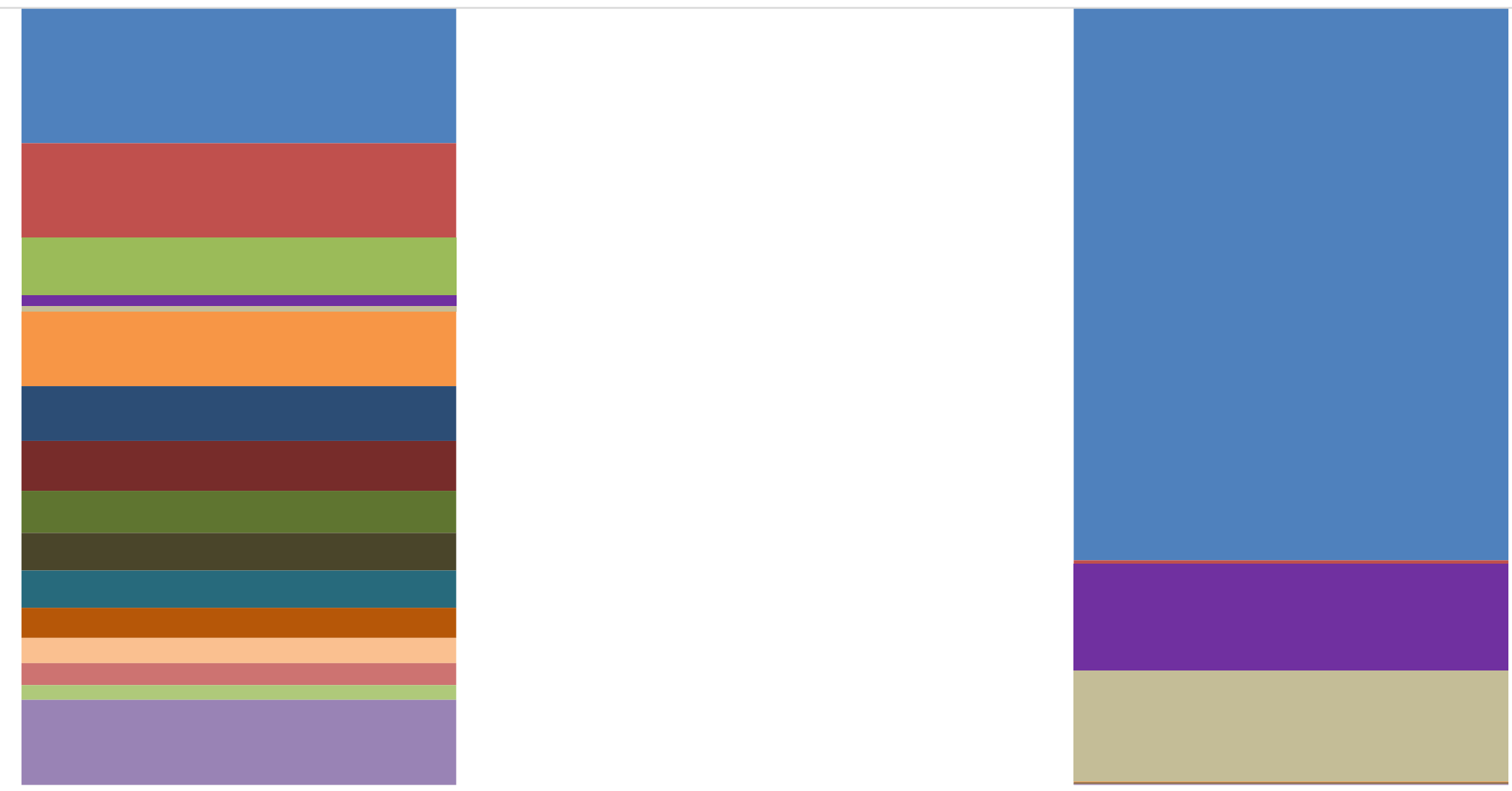

- Proteobacteria

- Bacteroidetes

- Archaea_unclassified

- Acidobacteria
- Chloroflexi

- Bathyarchaeota

- Omnitrophica

- Aminicenantes
Chlorobi

- Nitrospirae

- Planctomycetes

- Thaumarchaeota
- Firmicutes

- Bacteria unclassified

- Euryarchaeota

- Other 


\section{Conclusion}

- With complex organic matter, methane production detected

- With easily available simple organic matter, iron reduction precedes methane production

- With complex organic matter, fermentation acts as rate limiting step 